\title{
STATISTICAL ASSESSMENT OF DIFFERENT WAYS OF CALCULATING LAND EQUIVALENT RATIOS (LER)
}

\author{
By B. A. OYEJOLA and R. MEAD \\ Department of Applied Statistics, University of Reading, Reading RG6 $2 A N$ \\ (Accepted 23 October 1981)

\begin{abstract}
SUMMAR Y
The use in analysis of variance of six different ways of calculating the Land Equivalent Ratio (LER) was assessed. Criteria used are (1) normality of the residuals of LER values after fitting block and treatment effects, (2) precision of comparisons arising from the analysis of variance, and (3) possible bias in the means. These were examined in detail for data from one experiment and consistency of the results was investigated for seven other sets of data. Separate standardization in each block had no advantages over using the same standardization in all blocks. The use of many different divisors can lead to problems in the statistical analysis of LERs.
\end{abstract}

Research into intercropping is expanding rapidly and data from intercropping experiments are being analysed in many different ways. While we agree with the view (Mead and Stern, 1979) that no single form of analysis is appropriate for all intercropping experiments, and that several different analyses should be used for most intercropping experiments, we believe it is necessary to try to assess the benefits and disadvantages of different methods of analysis. One frequently-used index of combined yield from intercropping data is the Land Equivalent Ratio (LER) (Willey and Osiru, 1972; Willey, 1979), defined as the relative land area required to produce, from sole crops, the same yields as are achieved by intercropping. Using the notation of Mead and Willey (1980),

$$
\mathrm{LER}=\mathrm{L}=\mathrm{L}_{\mathrm{A}}+\mathrm{L}_{\mathrm{B}}=\mathrm{M}_{\mathrm{A}} / \mathrm{S}_{\mathrm{A}}+\mathrm{M}_{\mathrm{B}} / \mathrm{S}_{\mathrm{B}}
$$

and

$$
\lambda=\mathrm{L}_{\mathrm{A}} / \mathrm{L}
$$

when, $M_{A}, M_{B}$ are the component crop yields from an intercropping mixture, $\mathrm{S}_{\mathrm{A}}, \mathrm{S}_{\mathrm{B}}$ are the corresponding sole crop yields, which can be thought of as standardizing factors for the mixture yields,

$\mathrm{L}_{\mathrm{A}}, \mathrm{L}_{\mathrm{B}}$ are the component LERs for the two individual crops, and

$\lambda$ is the proportion of component A crop to the total LER, referred to in the text as the component LER proportion.

In using the LER as an index of yield advantage, and comparing different intercrop mixture treatments (for the same two component crops), various different philosophies have been advanced for choosing $S_{A}, S_{B}$. Huxley and Maingu (1978) argued that all intercrop yields should be compared with the sole crop when the latter is grown at optimum population and spacing. Mead and Willey distinguished different situations for which it may be argued that $S_{A}$ and $S_{B}$ should be either (a) the best achievable sole crop yields, or (b) the yields achieved when the sole crops are treated exactly like the intercrop mixture of 
the two crops. If an experiment to compare different genotypes for one or both crops aims to determine the highest-yielding combination overall, comparisons should be made with the highest-yielding sole crop genotypes. For different fertilizer levels, it may be more appropriate to standardize any given intercrop yield with respect to the sole crop yields at the same fertility level when comparing yield advantage at different fertilizer levels. Since farmers may not be able to change their fertility level, it must therefore be possible to compare intercropping and sole cropping at each of several levels of fertility. Mead and Stern (1980) have argued that sole crop yields for standardizing intercropping yields in the calculation of the LER should in some situations be simply an estimate of average sole crop yield.

- Although decisions about standardizing intercrop yields must depend on the particular agronomic situation, there are also statistical considerations in choosing which $S_{A}, S_{B}$ to use. In particular, what are the distributional properties of LERs calculated in the different possible ways? And are there any consistent differences in the precision of LERs using different standardizations? A further area of choice for experiments using a randomized block design is introduced by Fisher $(1977,1979)$, who considers standardization by sole crop yields for each block separately rather than by sole crop mean yields over the whole experiment. Fisher argued that standardization within each block should reduce standard errors as well as skewness of the distribution of residuals of LER values.

From a theoretical viewpoint there are good statistical reasons why the sum of two ratios of normal variables might not be normally distributed. It has been shown by Marsaglia (1965) that the distribution of the ratio of two non-negative normal variables can take many different forms, ranging from unimodal symmetrical curves to bimodal, positively-skewed curves with extreme kurtosis. However, the most common form of distribution for a ratio is unimodal and positively skewed, because of the possibility of small values for the divisor. LER values, which are obtained as sums of two such ratios, might therefore be expected to show some positive skewness. The use of many different divisors might also be expected to produce much more variable results, because of the two sources of variation in numerator and denominator. These effects might be of sufficient size to render the analysis invalid, or might merely produce relatively small quantitative changes in significance levels.

The investigation of six different forms of LER standardization is discussed in detail for one set of data (DataSet 1), and the consistency of results is then examined for seven other sets of data.

\section{DETAILED INVESTIGATION FOR ONE SET OF DATA}

\section{Description of DataSet 1}

- This set of data was obtained from a 4 millet $\times 4$ sorghum genotype experiment carried out at the International Crops Research Institute for the Semi- 
Arid Tropics (ICRISAT), Hyderabad, India in 1976. The 16 genotype combinations for the mixtures, plus the eight corresponding sole crop genotypes, were arranged in four randomized blocks of 24 plots each.

Analysis of yields from sole crop plots showed no significant $(P=0.05)$ block variation for either crop. The sole crop mean yields ranged from 797 to 2031 $\mathrm{kg} / \mathrm{ha}$ for millet genotypes and 1383 to $3112 \mathrm{~kg} / \mathrm{ha}$ for sorghum genotypes. For each crop the yields from mixtures were affected significantly $(\mathrm{P}=0.01)$ by the genotypes of that crop and of the competing crop, but there was little evidence of interaction effects. The mean yields of millet from mixtures varied between 422 and $2086 \mathrm{~kg} / \mathrm{ha}$, and of sorghum between 195 and $1976 \mathrm{~kg} / \mathrm{ha}$.

\section{Standardization methods}

The choice of sole crop yields as divisors in calculating LERs essentially defines the method of standardizing mixture yields. In this investigation three different choices of sole crop yield are considered, namely (a) the average of all sole crop yields, (b) yield for the corresponding sole crop treatment, or (c) yield for the best sole crop treatment. Each of these three definitions is applied, using sole crop yields in each block to calculate the LERs for plots in that block, and also with sole crop yields averaged over blocks. The definitions of the six methods of standardization, referred to hereafter as $\mathrm{L}_{1}$ to $\mathrm{L}_{6}$, are given in Table 1.

To illustrate the calculations using these methods we have taken the yields of all six combinations of two millet genotypes with three sorghum genotypes for all four blocks - a subset of DataSet 1 . The sole and mixed crop yields are given in Table 2, where the millet genotypes are represented by a and b, and the sorghum genotypes by A, B and C. The appropriate divisors (derived only from sole crop yields within the subset data) to be used to standardize mixed crop yields for $L_{1}$ to $L_{6}$ are given in Table 3 . Note that the magnitude of the divisors varies considerably between different standardizations, so that average LER values for $\mathrm{L}_{3}$ and $\mathrm{L}_{6}$ will be much smaller than those for the other definitions. Note also that the sorghum genotype giving the maximum sole crop yield for method 6 varies between blocks ( $\mathrm{C}$ in blocks 1,3 and 4, B in block 2). The component LERs, $\mathrm{L}_{\mathrm{A}}$ and $\mathrm{L}_{\mathrm{B}}$, are shown in Table 4 for standardization methods 1 and 5. The most obvious difference between the results for the two methods is the greater consistency across blocks of method 1 .

\section{Table 1. Definition of six methods of standardization}

In each of the six methods, the component crop yields from an intercropping mixture are standardized by the corresponding sole crop yields; the choice of sole crop yields are defined by:

$\mathrm{L}_{1}$ - The average of all treatments from all blocks,

$\mathbf{L}_{2}$ - The average of each treatment from all blocks,

$\mathrm{L}_{3}$ - The average of the best treatment from all blocks,

$\mathbf{L}_{4}$ - The average of all treatments from each block,

$\mathrm{L}_{5}$ - The average of each treatment from each block, and

$\mathrm{L}_{6}$ - The average of the best treatment from each block. 
Table 2. Yields (kg/ha) of sub-set of DataSet 1

\begin{tabular}{|c|c|c|c|c|c|c|c|c|}
\hline \multirow[b]{3}{*}{ Genotypes } & \multirow{2}{*}{\multicolumn{4}{|c|}{$\begin{array}{l}\text { Sole millet yield } \\
\text { Blocks }\end{array}$}} & \multirow{2}{*}{\multicolumn{4}{|c|}{$\begin{array}{c}\text { Sole sorghum yield } \\
\text { Blocks }\end{array}$}} \\
\hline & & & & & & & & \\
\hline & 1 & 2 & 3 & 4 & 1 & 2 & 3 & 4 \\
\hline $\mathbf{a}$ & 611 & 877 & 901 & 796 & & & & \\
\hline b & 2117 & 1877 & 2167 & 1951 & & & & \\
\hline A & & & & & 1296 & 1568 & 1019 & 1635 \\
\hline B & & & & & 1315 & 3210 & 2352 & 2790 \\
\hline \multirow[t]{3}{*}{ C } & & & & & 2944 & 2179 & 3432 & 3882 \\
\hline & & \multirow{2}{*}{\multicolumn{4}{|c|}{ Intercrop yields }} & \multirow{2}{*}{\multicolumn{3}{|c|}{ Sorghum }} \\
\hline & & & & & & & & \\
\hline aA & 556 & 1006 & 1012 & 790 & 253 & 346 & 241 & 543 \\
\hline $\mathbf{a B}$ & 642 & 562 & 426 & 290 & 617 & 556 & 1142 & 1031 \\
\hline $\mathrm{aC}$ & 580 & 358 & 407 & 340 & 1506 & 1543 & 1105 & 2389 \\
\hline bA & 1846 & 2617 & 1944 & 1932 & 148 & 56 & 321 & 253 \\
\hline bB & 1296 & 1632 & 1802 & 1043 & 1296 & 938 & 741 & 772 \\
\hline $\mathrm{bC}$ & 1481 & 1586 & 1549 & 1235 & 1290 & 685 & 1315 & 1389 \\
\hline
\end{tabular}

Assessment of effects

The effects of the different methods of standardisation are assessed in three ways. First, to examine the assumption of the analysis of variance that the observations are normally distributed, the residuals of the observations after fitting block and treatment effects are calculated and coefficients of skewness and kurtosis calculated. The information available from residuals is limited because they are inter-related but the two coefficients should provide evidence of whether the underlying distribution of observations differs markedly from the normal distribution, either in the sense of being non-symmetrical or more plateau-like or peaked.

Secondly, the precision of comparisons arising from the analysis of variance is examined by considering the residual sum of squares of the analysis, and the standard errors of treatment differences. A simple comparison of the values for the six different standardizations is not valid for either of these two measures.

Table 3. Divisors, obtained from sole crop yields, for six methods of calculating $L E R$ values from intercrop yields

\begin{tabular}{|c|c|c|c|c|c|}
\hline \multirow[b]{3}{*}{ Method } & \multicolumn{5}{|c|}{ Millet } \\
\hline & \multirow[b]{2}{*}{ Combinations } & \multicolumn{4}{|c|}{ Blocks } \\
\hline & & 1 & 2 & 3 & 4 \\
\hline 1 & all & \multicolumn{4}{|c|}{1142} \\
\hline \multirow[t]{2}{*}{2} & $\overrightarrow{\mathrm{aA}}, \mathrm{aB}, \mathrm{aC}$ & \multirow{2}{*}{\multicolumn{4}{|c|}{$\begin{array}{r}796 \\
2027\end{array}$}} \\
\hline & $\mathrm{bA}, \mathrm{bB}, \mathrm{bC}$ & & & & \\
\hline 3 & all & \multicolumn{4}{|c|}{2027} \\
\hline 4 & all & 1364 & 1377 & 1534 & 1373 \\
\hline \multirow[t]{2}{*}{5} & $\mathrm{aA}, \mathrm{aB}, \mathrm{aC}$ & 611 & 877 & 901 & 796 \\
\hline & $\mathrm{bA}, \mathrm{bB}, \mathrm{bC}$ & 2117 & 1871 & 2167 & 1951 \\
\hline 6 & all & 2117 & 1871 & 2167 & 1951 \\
\hline
\end{tabular}

\begin{tabular}{llccc}
\multicolumn{5}{c}{ Sorghum } \\
\hline & \multicolumn{4}{c}{ Blocks } \\
\cline { 2 - 5 } Combinations & 1 & 2 & 3 & 4 \\
all & \multicolumn{4}{c}{2302} \\
aA, bA & \multicolumn{4}{c}{1380} \\
aB, bB & \multicolumn{4}{c}{2417} \\
aC, bC & \multicolumn{4}{c}{3110} \\
all & \multicolumn{4}{c}{3110} \\
all & 1852 & 2319 & 2267 & 2770 \\
aA, bA & 1296 & 1568 & 1019 & 1635 \\
aB, bB & 1315 & 3210 & 2352 & 2790 \\
aC, bC & 2944 & 2179 & 3432 & 3882 \\
all & 2944 & 3210 & 3432 & 3882
\end{tabular}


Table 4. Calculated LER values, using methods 1 and 5

\begin{tabular}{|c|c|c|c|c|c|c|c|c|}
\hline \multirow[b]{2}{*}{ Combinations } & \multicolumn{4}{|c|}{$\begin{array}{c}\text { L A } \\
\text { Blocks }\end{array}$} & \multicolumn{4}{|c|}{$\begin{array}{c}\text { L A } \\
\text { Blocks }\end{array}$} \\
\hline & 1 & 2 & 3 & 4 & 1 & 2 & 3 & 4 \\
\hline \multicolumn{9}{|c|}{ Method 1} \\
\hline aA & 0.39 & 0.71 & 0.72 & 0.56 & 0.11 & 0.15 & 0.10 & 0.24 \\
\hline $\mathbf{a B}$ & 0.45 & 0.40 & 0.30 & 0.21 & 0.27 & 0.24 & 0.50 & 0.45 \\
\hline aC & 0.41 & 0.25 & 0.29 & 0.24 & 0.65 & 0.67 & 0.48 & 1.04 \\
\hline bA & 1.31 & 1.85 & 1.38 & 1.37 & 0.06 & 0.02 & 0.14 & 0.11 \\
\hline bB & 0.92 & 1.15 & 1.28 & 0.74 & 0.56 & 0.41 & 0.32 & 0.34 \\
\hline bC & 1.05 & 1.12 & 1.10 & 0.87 & 0.56 & 0.30 & 0.57 & 0.60 \\
\hline \multicolumn{9}{|c|}{ Method 5} \\
\hline aA & 0.91 & 1.15 & 1.12 & 0.99 & 0.20 & 0.23 & 0.24 & 0.33 \\
\hline aB & 1.05 & 0.64 & 0.47 & 0.36 & 0.46 & 0.17 & 0.49 & 0.37 \\
\hline $\mathrm{aC}$ & 0.95 & 0.41 & 0.45 & 0.43 & 0.51 & 0.71 & 0.32 & 0.62 \\
\hline bA & 0.38 & 1.39 & 0.90 & 0.99 & 0.11 & 0.03 & 0.32 & 0.15 \\
\hline bB & 0.27 & 0.87 & 0.83 & 0.53 & 0.99 & 0.29 & 0.31 & 0.28 \\
\hline bC & 0.31 & 0.85 & 0.72 & 0.63 & 0.44 & 0.31 & 0.38 & 0.36 \\
\hline
\end{tabular}

Because the standardizations use divisors of consistently different magnitudes in calculating the LERs for analysis, the absolute size of the LERs is different for the different standardisations, which will affect both sums of squares and standard errors. It is therefore appropriate to consider the standard error as a percentage of the overall mean (the coefficient of variation), and the residual SS as a proportion of the total SS; however, some standardizations $\left(\mathrm{L}_{4}, \mathrm{~L}_{5}, \mathrm{~L}_{6}\right)$ attempt to eliminate block differences, and the total SS to which it is relevant to compare the residual SS is the total SS after eliminating block variation.

The third characteristic examined is the possible bias of the six standardizations. Since the 'correct' value of LER for experimental data is inevitably unknown, no absolute measure of bias is possible, and the biasses of different standardizations must be discussed relative to each other.

For the full 64 observations of DataSet 1 , a standard analysis of variance for 4 blocks $\times 16$ treatments is calculated for each component $\left(\mathrm{L}_{A}\right.$ and $\left.L_{B}\right)$ and for the full LER(L) for each of the six standardizations $\mathrm{L}_{1}$ to $\mathrm{L}_{6}$. An analysis of variance is also calculated for the millet component LER proportion $\left(\lambda=\mathrm{L}_{\mathrm{A}} / \mathrm{L}\right)$ and for the original sole crop yields $\left(S_{A}, S_{B}\right)$ and mixture yields $\left(M_{A}, M_{B}\right)$. From each analysis the 64 residuals are obtained and five statistics calculated to summarize the distributional properties of the residuals (Table 5), namely

Skewness coefficient, $b_{1}=\left(\beta_{3} / \beta_{2}\right)^{3 / 2}$, where $\beta_{2}$ and $\beta_{3}$ are the second and third moments of the distribution of residuals,

Kurtosis coefficient, $b_{2}=\left(\beta_{4} / \beta_{2}\right)-3$, where $\beta_{4}$ is the fourth moment of the distribution of residuals,

The coefficient of variation = residual standard error/overall mean,

The residual SS/(total SS - block SS), and

The overall mean value averaged over all treatments. 
Table 5. Results of analysis of $L, L_{A}, L_{B}$ and $\lambda$ (for six standardization methods) $S_{A}, S_{B}, M_{A}$ and $M_{B}$

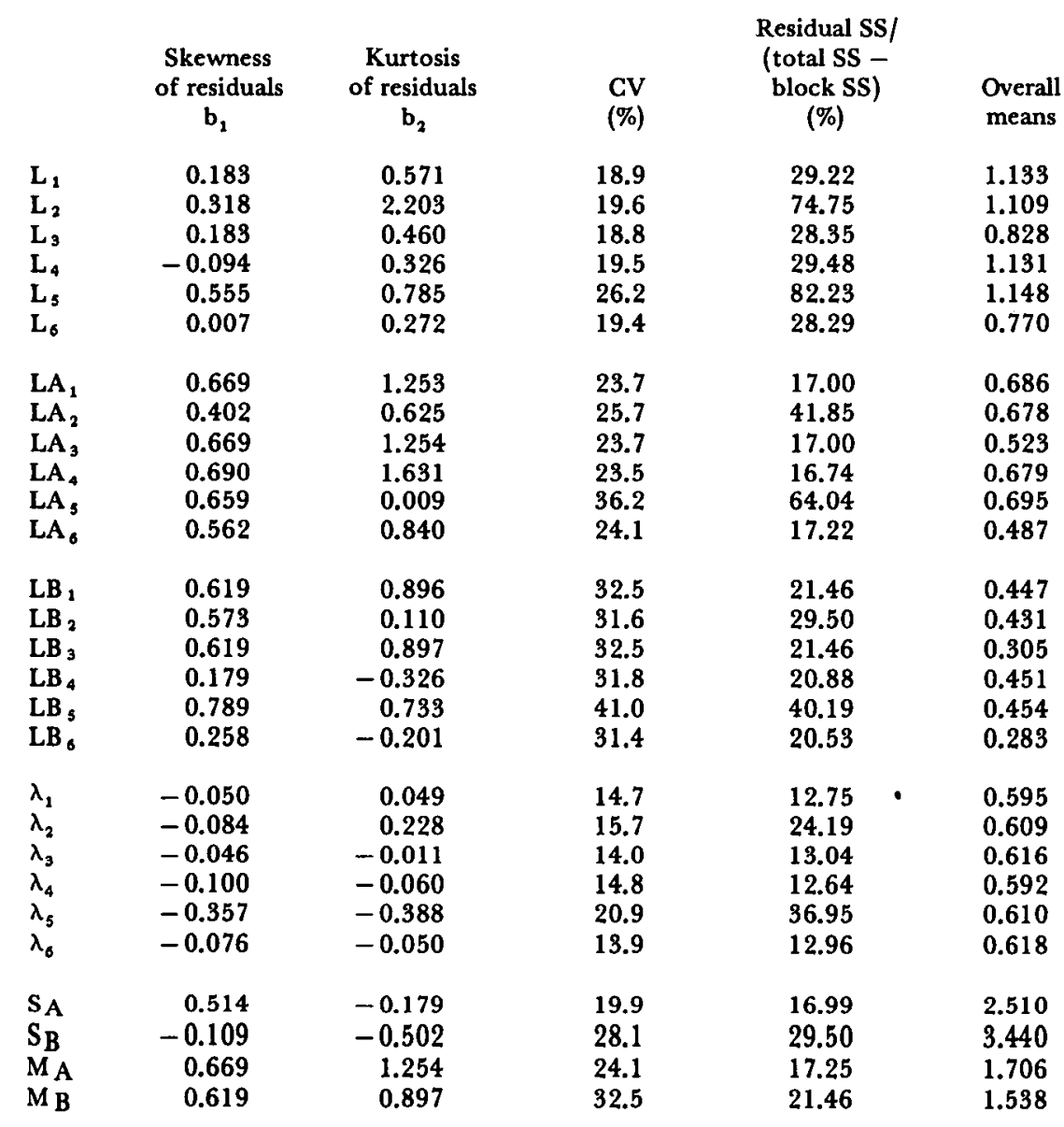

\section{Skewness and kurtosis}

Except for $L_{2}$ and $L_{5}$, coefficients of skewness and kurtosis from the LER values are small. The skewness coefficients of between -0.094 and 0.183 , and those of kurtosis, between 0.27 and 0.58 , obtained for $\mathrm{L}_{1}, \mathrm{~L}_{3}, \mathrm{~L}_{4}$ and $\mathrm{L}_{6}$, suggest that the residuals of the LER values are fairly normally distributed. According to Srivastava (1959), the power of the analysis of variance tests carried out on values with such residuals would not be affected. Standardization based on the mean sole crop yield for each treatment $\left(\mathrm{L}_{2}\right)$ produces values which are fairly skewed, though moderate enough to be valid for analysis of variance tests, but the skewness is increased if this method is used separately in each block $\left(L_{5}\right)$. The residuals of the LER values show less skewness and less extreme kurtosis than those of the LER components except for methods 2 and 5 . The differences between standardization by the average of all treatments and the average of the best treatment $\left(\mathrm{L}_{1}\right.$ and $\mathrm{L}_{3}, \mathrm{~L}_{4}$ and $\left.\mathrm{L}_{6}\right)$ are small.

The component LER proportion $\lambda_{\mathrm{A}}$ shows less extreme kurtosis and skewness 
than the LER values. Except for the $L_{5}$ standardization, residuals from the LER values do not indicate such non-normality as to affect the power of the analysis of variance tests.

\section{Precision}

The coefficient of variation, CV, of the LER values when method 5 is used are higher than for the other methods. The proportion $\lambda_{\mathrm{A}}$ gave lower values than the LER, and again method 5 is clearly more variable. The percentage of unexplained variation was lower than $30 \%$ for $L_{1}, L_{3}, L_{4}$ and $L_{6}$, increasing by up to $50 \%$ to give $74.8 \%$ and $82.2 \%$ for $\mathrm{L}_{2}$ and $\mathrm{L}_{5}$ respectively. The amounts of unexplained variation for the LER values were higher than for their components and also than for the intercrop yields. Those for the component LER proportion were lower than $13 \%$ for $\lambda_{1}, \lambda_{3}, \lambda_{4}$ and $\lambda_{6}$ and up to 24 and $37 \%$ for $\lambda_{2}$ and $\lambda_{5}$ respectively.

\section{Means (relative bias)}

Standardization by the best sole crop yield $\left(\mathrm{L}_{3}\right.$ and $\left.\mathrm{L}_{6}\right)$ inevitably gave lower means than the other methods, whether standardization was done separately in each block or not. The variation in mean values for the other four methods seems small though this is, of course, difficult to assess from a single set of data.

\section{OTHER DATA SETS USED FOR ANALYSIS}

\section{Set 2}

A similar experiment to that described for Set 1 was carried out in 1977; the results from the analysis of the yields from the sole plots were similar to those of Set 1, with ranges of mean yields for millet and sorghum of 1083 to 2124 $\mathrm{kg} / \mathrm{ha}$ and 1907 to $3744 \mathrm{~kg} / \mathrm{ha}$ respectively. In the mixtures, the presence of different sorghum genotypes did not significantly $(\mathrm{P}=0.05)$ affect millet yields, but there was a significant $(\mathrm{P}=0.01)$ interaction effect of both sets of genotypes on the sorghum yields. The mean yields of millet in the mixtures were between 725 and $1602 \mathrm{~kg} / \mathrm{ha}$, while for sorghum mean yields varied between 462 and $2551 \mathrm{~kg} / \mathrm{ha}$.

\section{Set 3}

This set of data came from a sorghum-pigeonpea intercropping experiment carried out at ICRISAT in 1977/78. Six population densities of sorghum were combined with four nitrogen levels applied only to the sorghum plants. Sole crop plots of sorghum at each nitrogen level, and one pigeonpea sole crop plot, were included. There were four blocks and the nitrogen levels were applied to split plots.

The mean yield for pigeonpea from the sole plots was $1.4 \mathrm{~kg} / \mathrm{plot}$ while the mean yields for sorghum varied between 2.7 and $6.7 \mathrm{~kg} / \mathrm{plot}$. There was a large 
effect of nitrogen on the sole crop sorghum yields as well as considerable block variation. In the mixtures, changes in population levels of sorghum significantly $(P=0.05)$ affected the pigeonpea yields. For sorghum yields there were no significant changes with changes in populations, but yields increased with increasing nitrogen levels, the means for sorghum ranging between 1.77 and 5.68 $\mathrm{kg} / \mathrm{plot}$.

\section{Set 4}

Another ICRISAT genotype experiment in 1978 involved all 12 combinations of three millet and four groundnut genotypes, together with all crops grown sole. Four blocks of a criss-cross design were used. There were large block differences; sole crop millet yields were between 2590 and $3285 \mathrm{~kg} / \mathrm{ha}$ whilst sole crop yields of the groundnut genotypes were significantly different $(P=$ 0.01 ), varying between 906 and $1701 \mathrm{~kg} / \mathrm{ha}$. In the mixtures, the yields of component crops were apparently affected only by the crop genotypes; yields of millet varied between 1691 and $3344 \mathrm{~kg} / \mathrm{ha}$ and those of groundnut between 1274 and $3086 \mathrm{~kg} / \mathrm{ha}$.

\section{Set 5}

This set, also from ICRISAT, was from a 4 pigeonpea $\times 3$ maize population density experiment. One pigeonpea population density and the three maize population densities were used for sole plots. The $(3 \times 4)+4$ treatments were arranged in four randomized blocks. Both sole crop and mixture yields appeared to vary little with population level. The mean yield for pigeonpea from sole plots was $1.7 \mathrm{~kg} / \mathrm{plot}$ and for maize between 6.0 and $6.4 \mathrm{~kg} / \mathrm{plot}$. For the mixtures the mean yields for pigeonpea were between 0.86 and $1.28 \mathrm{~kg} / \mathrm{plot}$ and between 5.2 and $6.3 \mathrm{~kg} / \mathrm{plot}$ for maize.

\section{Set 6}

This set was collected at the All India Coordinated Research Project for Dryland Agriculture (AICRPDA), Hyderabad. The experiment consisted of four ratios of sorghum density to pigeonpea density for two row spacings between the crops, arranged in three randomized blocks, with sole crop plots for both row spacings. Sole crop yields of sorghum were significantly $(\mathrm{P}=0.05)$ different for the two row spacings, with mean yields of 3587 and $4313 \mathrm{~kg} / \mathrm{ha}$. The mean sole crop pigeonpea yield was $2040 \mathrm{~kg} / \mathrm{ha}$. Mixture yields were substantially affected by changes in both population and row spacing. Mean yields of pigeonpea varied between 617 and $2343 \mathrm{~kg} / \mathrm{ha}$ and those of sorghum between 897 and $4010 \mathrm{~kg} / \mathrm{ha}$.

\section{Set 7}

In a second experiment at AICRPDA, two varieties at four population levels of pigeonpea were intersown with a single sorghum genotype. These treatments, with the two varieties of pigeonpea and the sorghum genotype, both at one 
population level for the sole plots, were arranged in four randomized blocks. The mean sole crop pigeonpea yield was $1102 \mathrm{~kg} / \mathrm{ha}$. The mean mixture yield of sorghum was $2337 \mathrm{~kg} / \mathrm{ha}$. There were significant $(\mathrm{P}=0.01)$ differences in the mixture yields of the two varieties of pigeonpea and in the yields at different population levels. The mean mixture yields of pigeonpea varied between 477 and $913 \mathrm{~kg} / \mathrm{ha}$.

\section{Set 8}

The experiment from which these data were collected was carried out at the Institute for Agricultural Research, Samaru, Nigeria in 1975, with cotton sown at four dates, as a sole crop and mixed with four cereals. The cereals were sown on the first date, whether they were to be grown sole or subsequently intersown with cotton. Three randomized blocks were used. Two of the mixture combinations gave very low yields for both crops, resulting in a very high CV and highly skewed residuals. Yields for only the remaining 14 combinations have been considered.

There were large differences between the sole crop yields of the cereals, varying between 1096 and $4984 \mathrm{~kg} / \mathrm{ha}$. Planting date affected seed cotton yields from sole plots, means varying between 368 and $2019 \mathrm{~kg} / \mathrm{ha}$. The yields of the cereals varied significantly for the fourteen combinations. Though the factorial structure was lost, the date when the cotton was planted did not affect the cereal yields. Seed cotton yield was significantly affected by both the type of cereal with which it was intersown as well as by the planting date; mean cereal yields of the cereals varied between 913 and $5398 \mathrm{~kg} / \mathrm{ha}$, and cotton yields between 131 and $1240 \mathrm{~kg} / \mathrm{ha}$.

\section{RESULTS FOR ALL DATA SETS}

\section{Normality}

Coefficients of skewness and kurtosis for the six standardization methods are summarized in Table 6, both for the total LER and the component LER proportion. Results for other variables show very much the same characteristics as for DataSet 1 (Table 5) and are not presented. The pattern of results varies between the eight sets (referred to as Experiments 1-8 below) but some general conclusions can be drawn.

Considering first the LER results, $\mathrm{L}_{2}$ and $\mathrm{L}_{5}$ give rather different results from the other four standardization methods, and these two standardizations, which use different divisors for each treatment, generally give more evidence of nonnormality. The exception is Expt 8 where the standardizations $\mathrm{L}_{4}$ and $\mathrm{L}_{6}$, which use different divisors for each block, give rather more extreme coefficients. The results for $L_{1}$ and $L_{3}$ are very similar, which is not surprising since these two standardizations use the same number of divisors. The same is true for $L_{4}$ and $L_{6}$. Comparing $L_{1}$ and $L_{3}$, which use the same standardization for all blocks, with $\mathrm{L}_{4}$ and $\mathrm{L}_{6}$, which use different ones for each block, gives no clear- 
Table 6. Non-normality in the residuals of LER values and of component LER proportions for six standardization methods

Experiment

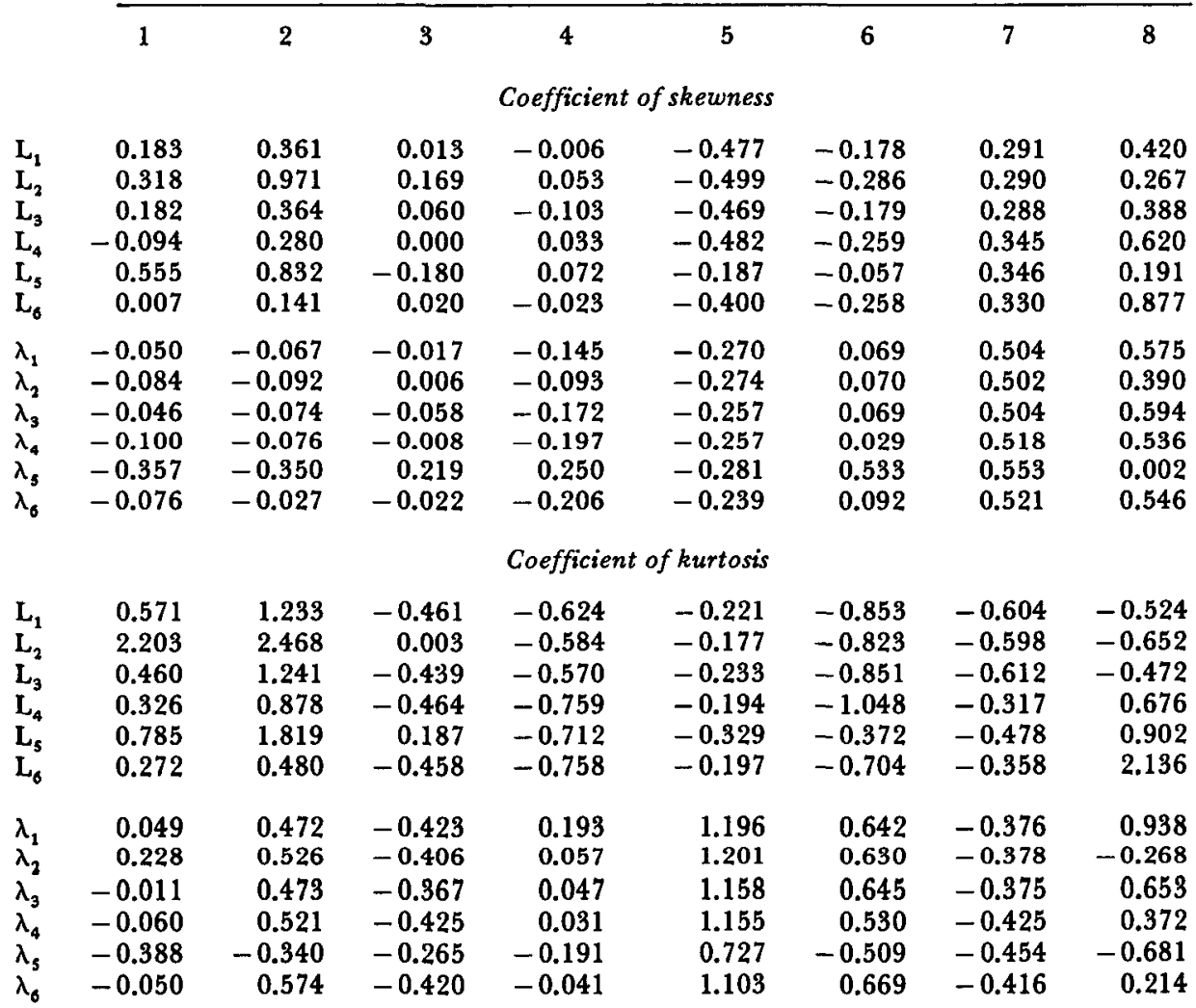

cut advantage to either philosophy except for the better results of $L_{1}$ and $L_{3}$ in Expt 8.

As would be expected for ratios of variables, the distributions tend to be positively skewed, the main exception being in Expt 5, where the original distributions of both component crops are negatively skewed. Over all eight experiments any of the standardizations $\mathrm{L}_{1}, \mathrm{~L}_{3}, \mathrm{~L}_{4}$ and $\mathrm{L}_{6}$ appear acceptably normal, with $L_{1}$ and $L_{3}$ seeming slightly better. The results for the component LER proportion, $\lambda$, show very good agreement with normal distributions and there seems to be little to choose between the standardisation methods.

\section{Precision}

The CVs for the different standardization methods for each experiment are shown in Table 7, and whilst Table 8 shows the residual SS expressed as a proportion of the total sum of squares. The first criterion is a measure of the precision of individual treatment means, with a correction to allow for absolute differences of scale for the different standardizations. The second measures random variation relative to the overall treatment variation. Within each experi- 
Table 7. Coefficients of variation of $L$ and $\lambda$ for six standardization methods

\begin{tabular}{rrrrrrrr}
\multicolumn{7}{c}{ Experiment } \\
\hline 1 & 2 & 3 & 4 & 5 & 6 & 7 & 8 \\
18.9 & 15.4 & 13.4 & 8.6 & 11.2 & 10.9 & 10.6 & 9.7 \\
19.6 & 17.4 & 14.6 & 9.0 & 11.2 & 10.9 & 10.6 & 9.7 \\
18.8 & 15.5 & 13.4 & 8.4 & 11.2 & 10.8 & 10.6 & 11.3 \\
19.5 & 16.6 & 12.2 & 9.0 & 11.2 & 10.4 & 11.1 & 12.8 \\
26.2 & 34.9 & 14.9 & 10.0 & 13.1 & 14.9 & 10.8 & 30.5 \\
19.4 & 15.9 & 12.6 & 8.9 & 11.1 & 9.4 & 11.2 & 11.9 \\
14.7 & 11.5 & 15.4 & 13.8 & 10.4 & 6.4 & 16.8 & 8.3 \\
15.7 & 10.7 & 20.3 & 13.8 & 10.4 & 6.4 & 16.8 & 7.7 \\
14.0 & 11.3 & 13.6 & 12.3 & 10.6 & 6.4 & 16.9 & 9.1 \\
14.8 & 10.6 & 15.8 & 13.6 & 10.4 & 6.5 & 16.5 & 9.0 \\
20.9 & 13.3 & 18.5 & 14.3 & 10.7 & 9.3 & 16.1 & 16.2 \\
13.9 & 11.3 & 15.1 & 12.3 & 10.8 & 6.3 & 16.8 & 9.3
\end{tabular}

ment the CVs are remarkably similar for the different standardizations except for $\mathrm{L}_{5}$, which gives much more variable results. Standardizing by the same divisors over all blocks $\left(\mathrm{L}_{1}\right.$ and $\left.\mathrm{L}_{3}\right)$ gives marginally better precision than using different divisors for each block $\left(\mathrm{L}_{4}\right.$ and $\left.\mathrm{L}_{6}\right)$.

Results for the residual sums of squares also show general superiority of $L_{1}$, $L_{3}, L_{4}$ and $L_{6}$, with both $L_{2}$ and $L_{5}$ giving larger residuals. For this criterion the variation between experiments is particularly large. Experiment 5, with very small treatment effects, gives quite different results from Expt 8, with its complex treatment structure and wide variation of yields. The results for the component LER proportion $\lambda$ are again broadly similar to those for LERs with $L_{5}$ and to a lesser extent $\mathrm{L}_{2}$, giving lower precision and higher residual SS. The reason for the very small relative residual SS for Expt 6 is not clear, though it may be simply a reflection of the large variation of yields of both crops in the mix ture treatments.

Table 8. Residual SS/(total SS - block SS) of L and $\lambda$ for six standardization methods (expressed in percentages)

Experiment

\begin{tabular}{rrrrrrrr}
\hline 1 & 2 & 3 & 4 & 5 & 6 & 7 & 8 \\
29.22 & 31.86 & 26.77 & 15.60 & 73.81 & 41.96 & 45.86 & 3.39 \\
74.75 & 70.91 & 62.15 & 72.91 & 74.08 & 87.33 & 44.73 & 5.57 \\
28.35 & 33.42 & 33.90 & 17.40 & 73.52 & 41.93 & 46.15 & 4.02 \\
29.48 & 37.03 & 25.10 & 17.16 & 74.75 & 40.67 & 48.15 & 4.69 \\
82.23 & 79.92 & 52.57 & 53.10 & 80.29 & 91.61 & 45.30 & 28.62 \\
28.29 & 33.91 & 27.68 & 19.51 & 73.58 & 36.69 & 49.25 & 4.59 \\
12.75 & 21.65 & 25.70 & 26.48 & 74.21 & 1.63 & 63.75 & 6.49 \\
24.19 & 34.01 & 75.28 & 53.80 & 74.78 & 1.63 & 62.75 & 6.27 \\
13.04 & 21.59 & 26.28 & 25.36 & 74.17 & 1.64 & 63.78 & 6.14 \\
12.64 & 21.19 & 25.66 & 24.85 & 74.21 & 1.68 & 62.89 & 7.48 \\
36.95 & 46.25 & 82.89 & 36.77 & 76.01 & 3.35 & 60.18 & 22.41 \\
12.96 & 22.08 & 25.81 & 24.35 & 74.13 & 1.50 & 63.04 & 7.18
\end{tabular}


Bias

Two criteria are used to examine the extent to which there are consistent differences between the mean LERs obtained from different standardization methods. First, Table 9 examines the mean difference between the LERs given by different methods. Each of the other five methods of LER is compared with $\mathrm{L}_{1}$, and differences $\mathrm{L}_{2}-\mathrm{L}_{5}$ and $\mathrm{L}_{3}-\mathrm{L}_{6}$ are also investigated, because there have been suggestions that there might be a consistent bias between standardization methods that use a single divisor over all blocks and those using different divisors for each block.

Two standardization methods, $\mathrm{L}_{3}$ and $\mathrm{L}_{6}$, relate all mixed crop yields to the best sole crop yields. Hence the values of $\mathrm{L}_{3}$ and $\mathrm{L}_{6}$ are lower than for the other LERs except in Expts 5 and 6, where there was little variation in sole crop yields. The comparisons $\mathrm{L}_{1}-\mathrm{L}_{4}, \mathrm{~L}_{2}-\mathrm{L}_{5}$ and $\mathrm{L}_{3}-\mathrm{L}_{6}$ yield rather contradictory results. $L_{2}$ gives larger LERs than $L_{5}$ for all eight experiments, suggesting that using the same standardization for all blocks inflates the LER compared with separate block standardizations. However, $\mathrm{L}_{3}$ gives generally lower LERs than $\mathrm{L}_{6}$, suggesting the opposite conclusion, and the $\mathrm{L}_{1}-\mathrm{L}_{4}$ difference is not only variable in sign but consistently small.

A second aspect of bias is presented in Table 10, where the differences of mean LERs for different standardisations are calculated for each mixed crop treatment and the consistency of such differences expressed as the variance of the differences. The values tabulated in Table 9 are simply the means of the differences from which the variances in Table 10 are calculated.

Looking first at $\mathrm{L}_{1}-\mathrm{L}_{4}, \mathrm{~L}_{2}-\mathrm{L}_{5}$ and $\mathrm{L}_{3}-\mathrm{L}_{6}$ we see that there may have been consistent mean differences over the eight experiments, but the comparisons of LERs are extremely consistent over treatments, notably for $\mathrm{L}_{3}-\mathrm{L}_{6}$ where the variances are quite tiny. Put another way, comparisons of the treatments in terms of mean LER are virtually identical for $L_{3}$ and $L_{6}$, and also for $L_{1}$ and $\mathrm{L}_{3}$. For $\mathrm{L}_{2}$ and $\mathrm{L}_{5}$ it is clear that treatment comparisons may be rather different - a variance of 0.02 corresponds to a standard deviation of 0.14 , implying that the difference of LER for two treatments will change by about 0.14 if we change the standardization method from $\mathrm{L}_{2}$ to $\mathrm{L}_{5}$.

The standardizations which appear to give most inconsistent results are for

\section{Table 9. Mean differences between LERs from the standardization methods}

\begin{tabular}{llllllll}
\multicolumn{8}{c}{ Experiment } \\
\hline 1 & 2 & 3 & 4 & 5 & 6 & 7 & 8
\end{tabular}

$\begin{array}{lrrrrrrrr}\mathrm{L}_{1}-\mathrm{L}_{2} & 0.024 & 0.040 & 0.003 & 0.012 & 0.000 & 0.000 & 0.002 & -0.065 \\ \mathrm{~L}_{1}-\mathrm{L}_{3} & 0.304 & 0.348 & 0.171 & 0.320 & 0.032 & 0.006 & 0.105 & 0.728 \\ \mathrm{~L}_{1}-\mathrm{L}_{4} & 0.002 & 0.030 & -0.049 & 0.006 & -0.002 & -0.035 & 0.002 & -0.011 \\ \mathrm{~L}_{1}-\mathrm{L}_{5} & -0.027 & -0.062 & -0.031 & -0.054 & -0.008 & -0.035 & -0.011 & -0.212 \\ \mathrm{~L}_{1}-\mathrm{L}_{6} & 0.362 & 0.351 & 0.297 & 0.331 & 0.061 & -0.010 & 0.137 & 0.724 \\ \mathrm{~L}_{2}-\mathrm{L}_{5} & 0.051 & 0.102 & 0.034 & 0.066 & 0.007 & 0.035 & 0.013 & 0.147 \\ \mathrm{~L}_{3}-\mathrm{L}_{6} & -0.058 & -0.002 & -0.127 & -0.011 & -0.029 & 0.016 & -0.032 & 0.005\end{array}$


Table 10. Variances, over the treatment set, of differences.between LERs for different standardization methods

\begin{tabular}{|c|c|c|c|c|c|c|c|c|}
\hline & & & & Expe & nent & & & \\
\hline & 1 & 2 & 3 & 4 & 5 & 6 & 7 & 8 \\
\hline$L_{1}-L_{2}$ & 0.0890 & 0.0545 & 0.0592 & 0.0657 & 0.0006 & 0.0000 & 0.0146 & 0.6620 \\
\hline & 0.0059 & 0.0047 & 0.0032 & 0.0088 & 0.0000 & 0.0000 & 0.0001 & 0.1322 \\
\hline$L_{1}-L_{4}$ & 0.0009 & 0.0004 & 0.0003 & 0.0001 & 0.0000 & 0.0007 & 0.0000 & 0.0001 \\
\hline$L_{1}-L_{5}$ & 0.0884 & 0.0950 & 0.0850 & 0.0769 & 0.0005 & 0.0006 & 0.0163 & 0.8760 \\
\hline$L_{1}-L_{6}$ & 0.0075 & 0.0053 & 0.0030 & 0.0075 & 0.0000 & 0.0007 & 0.0005 & 0.1335 \\
\hline$L_{2}-L_{5}$ & 0.0020 & 0.0156 & 0.0034 & 0.0209 & 0.0000 & 0.0006 & 0.0001 & 0.0289 \\
\hline $\mathbf{L}_{3}-\mathbf{L}_{6}$ & 0.0004 & 0.0002 & 0.0003 & 0.0001 & 0.0000 & 0.0007 & 0.0002 & 0.0001 \\
\hline $\begin{array}{l}\text { Number of } \\
\text { treatments }\end{array}$ & 16 & 16 & 16 & 12 & 12 & 8 & 8 & 14 \\
\hline
\end{tabular}

$\mathrm{L}_{1}$ and $\mathrm{L}_{2}$, and $\mathrm{L}_{1}$ and $\mathrm{L}_{5}$. Whilst these comparisons did show some consistent bias in Table 9, with $L_{1}$ giving higher values than $L_{2}$ and lower than $L_{5}$, the variability of treatment comparisons is very large for Expts 1 to 4, reflecting the wide variation of sole crop mean. The consistent treatment differences over different standardizations shown for Expts 5 and 6 arise from the small variation in sole crop yields for these two experiments.

\section{CONCLUSIONS}

The statistical considerations investigated in this paper are only one aspect of the choice of how to calculate an LER. Nevertheless, the findings presented here are relevant to any comparison of LERs and in particular to any proposed analysis of variance of LERs. Generally, the more divisors required by a standardization method, the greater are the doubts about the validity of the normal distribution assumptions and the poorer is the precision of treatment comparison. This conclusion is not in any way surprising in the context of general statistical theory about the distribution of ratios.

Specific advice that we believe should follow from our results is that if the LER is calculated using the corresponding treatment sole crop yields as divisors, then the results using separate divisors for each block $\left(L_{5}\right)$ are highly unreliable and should not be used in an analysis of variance. If the same divisors are used for each block, then the results are more reliable though normality assumptions can still be rather doubtful.

For standardization methods using a single sole crop yield for each crop there is a slight advantage in using the same divisor for all blocks, both in terms of normality and precision. However, the advantage is slight for these eight experiments, and the two methods of standardization yield almost identical treatment comparisons, but further comparison of $\mathrm{L}_{1}$ or $\mathrm{L}_{3}$ with $\mathrm{L}_{4}$ or $\mathrm{L}_{6}$ on more sets of data may yield different conclusions. For the present we can detect no reason to use different divisors in different blocks. Unless there are good agronomic grounds against the choice, we recommend that the calculation of 
LERs for comparative purposes should use a single sole crop yield for each crop and that the same sole crop yield should be used for all blocks.

Regarding analysis and comparison of the ratio of crop component LERs, there is little to choose between standardization methods except that using different sole crop yields for different treatments can lead to rather imprecise results.

Acknowledgements. We are most grateful to the experimenters at the International Crop Research Institute for the Semi-Arid Tropics, Hyderabad, the All India Coordinated Research Project for Dryland Agriculture, Hyderabad, and the Institute for Agricultural Research, Samaru, without whose data the investigations reported in this paper could not have been achieved.

\section{REFERENCES}

Fisher, N. M. (1977). Studies in mixed cropping. 1. Seasonal difference in relative productivity of crop mixtures and pure stands in the Kenya Highlands. Experimental Agriculture 13:177-184.

Fisher, N. M. (1979). Studies in mixed cropping. 3. Further results with maize-bean mixtures, Experimental Agriculture 15:49-58.

Huxley, P. A. \& Maingu, Z. (1978). Use of a systematic spacing design as an aid to the study of intercropping: some general considerations. Experimental Agriculture 14:49-56.

Marsaglia, G. (1965). Ratios of normal variables and ratios of sums of uniform variables. Journal of the American Statistical Association 60:193-204.

Mead, R. \& Stern, R. D. (1979). Statistical considerations in experiments to investigate intercropping. In Proceedings of the Intermational Workshop on Intercropping. Hyderabad, India: ICRISAT.

Mead, R. \& Stern, R. D. (1980). Designing experiments for intercropping research. Experimental Agriculture 16:329-342.

Mead, R. \& Willey, R. W. (1980). The concept of a 'Land Equivalent Ratio' and advantages in yields from intercropping. Experimental Agriculture 16:217-228.

Srivastava, A. B. L. (1959). Effect of non-normality on the power of the analysis of variance test. Biometrika 46:114-122.

Willey, R. W. (1979). Intercropping - its importance and research needs. I. Competition and yield advantages. Field Crop Abstracts 32:1-10.

Willey, R. W. \& Osiru, D. S. (1972). Studies on mixtures of maize and beans (Phaseolus vulgaris) with particular reference to plant population. Joumal of Agricultural Science, Cambridge 79:519-529. 